\title{
Discriminação na longue durée: padrōes globais e estratégias locais
}

\author{
Discrimination in the longue durée: \\ global standards and local strategies
}

Manuela Boatcă

\section{Resumo}

A discriminação com base em raça, etnia, gênero, origem, constituição corporal ou nível educacional é uma característica específica da modernidade ocidental. Na contribuição que se segue, sustentaremos a tese de que a discriminação de migrantes e minorias étnicas parte da mesma lógica de inclusāo/exclusão que atrelou o projeto de construção de identidade dos estados nacionais modernos à patologização dos sujeitos (de direito) nas colônias extra-europeias. Trata-se, portanto, de um problema estrutural do sistema-mundo moderno que se manifesta em distintos contextos, como procuraremos ilustrar a partir de dois exemplos - os EUA e a Alemanha. Em cada um destes casos verifica-se uma autocompreensão distinta do que significa ser um 'país de imigração', tanto em termos socioculturais, quanto na forma que esta temática é apropriada politicamente. Busca-se, desta forma, explicitar as diferentes contextualizaçōes históricas das práticas de discriminação e as suas respectivas consequências para a postura destes países diante de migrantes e minorias étnicas.

Palavras-chave: discriminação, imigração, modernidade.

\begin{abstract}
Discrimination based on race, ethnicity, gender, origin, bodily constitution or educational level is a specific feature of Western modernity. In the following contribution, we will support the thesis that the discrimination of migrants and ethnic minorities is based on the same logic of inclusion / exclusion that linked the project of constructing the identity of modern nation states to the pathologization of subjects in the extra- European countries. It is, therefore, a structural problem of the modern world-system that manifests itself in different contexts, as we will try to illustrate from two examples - the US and Germany. In each of these cases there is a self-understanding distinct from what it means to be a 'country of immigration', both in sociocultural terms, and in the way that this issue is politically appropriate. In this way, the aim is to make explicit the different historical contextualizations of discrimination practices and their respective consequences for the posture of these countries vis-à-vis migrants and ethnic minorities.
\end{abstract}

Keywords: discrimination, immigration, modernity. 


\section{Introdução}

A discriminação baseada na raça, ${ }^{1}$ etnia, sexo, origem, constituição corporal ou nível de instrução é uma marca da modernidade ocidental. É verdade que, em sistemas sociais mais antigos, a alteridade também foi interpretada como uma ameaça à comunidade social. A lógica da xenofobia daí resultante, porém, ditava via de regra a exclusão física dos outros, diferentes ou "bárbaros" da comunidade ou do grupo - no caso extremo, por meio da morte (Wallerstein 1998: 44).

A modernidade europeia, ao contrário, foi o primeiro ordenamento social e político que - em conexão com o princípio iluminista da igualdade de todos os seres humanos independentemente da origem social - suscitou a demanda pela completa inclusão de seus membros mediante a introdução de critérios universalistas. Com a maior mobilidade social, a urbanização e a dissolução dos laços tradicionais, no entanto, a experiência da alteridade também foi generalizada nas sociedades industriais modernas e cada vez mais diferenciadas funcionalmente (cf. Hahn 1994: 162). A modernidade se tornou, paradoxalmente, o lugar de numerosas exclusōes que foram muito além da semântica, usual em todas as comunidades sociais, das delimitaçōes e exclusōes "do" outro, e que acabaram desembocando em "julgamentos sociais de desvalor" (Peters 1995: 30) expressos em diferentes tipos e graus de alteridade, tendo como consequência distintas formas de discriminação. Nacionalidade, sexo, raça, afiliação religiosa, orientação sexual e até mesmo a constituição corporal operaram sobre o pano de fundo do estabelecimento moderno de normas não só de forma a instituir identidades, mas antes de tudo como geradores de alteridade. Mas, uma vez que na modernidade a eliminação física do diferente não representava mais um meio legítimo para a produção de um ordenamento social racional (razão pela qual foi rechaçado, sendo declarado um ato irracional de exceção, o extermínio sistemático de judeus, católicos, ciganos, homossexuais e deficientes físicos durante a Segunda Guerra Mundial), a alteridade generalizada e seu estigma de algo ameaçador precisaram coexistir no novo tipo de sociedade.

As estratégias correspondentes de delimitação nutriram-se, consequentemente, da "metafísica do caráter unívoco da modernidade" (Beck 1995: 154), na medida em que construíram a identidade como algo uniforme, coerente e ordenado, e a alteridade, por contraste, como imprevisível, irracional e, portanto, antissocial. Sua polarização entre opostos sociais e naturais mutuamente excludentes legitimou, dessa maneira, estratégias de exclusão ou cooptação "do" outro como meio de controle do espaço social e fundamentou ao mesmo tempo uma visão de mundo dualista, característica da modernidade, na qual é obscurecida a esfera daquilo que há em comum (histórica, política, econômica, social e fisicamente) entre o outro e o próprio. As açōes de limitação e exclusão corresponderam, a partir de então, à lei do terceiro excluído - porque complexo, ambivalente ou indefinível -, lei que estava associada à produção de ordem como tarefa arquetípica da modernidade: "Já que a soberania do intelecto moderno é o poder de definir e de conferir efetividade às definiçōes, tudo aquilo que escapa à localização inequívoca é uma anomalia e um desafio" (Bauman 1992: 21).

Controlar as anomalias, criadas somente com a ajuda de uma classificação sistemática, torna-se a tarefa do Estado nacional moderno. A generalização da alteridade no ambiente social mais próximo foi acompanhada de processos de alienação do indivíduo como consequência da suspensão dos critérios de alocação e identificação, da perda de significado da comunidade religiosa

\footnotetext{
${ }^{1}$ Quando, no que segue, fala-se em "raça", não se quer dizer com isso a existência biológica de raças distintas, mas a sua construção social como um critério de distinçāo frequentemente instrumentalizado para processos de discriminaçāo - como o racismo e a racializaçāo. Sobre a abordagem do conceito de raça ou de race, que varia de acordo com contextos nacionais distintos e com a cultura científica, ver abaixo.
} 
como fonte de sentido e solidariedade, bem como da autonomia crescente dos sujeitos políticos. O aumento de liberdade - com relação tanto à autoridade divina quanto à feudal - teve como consequência, ao mesmo tempo, uma busca por novas afiliaçōes. Por isso, um modelo racional de integração social, tal como deveria ser realizado pelo "projeto iluminista da modernidade" (Habermas 1990), dependia, para a produção de identidade coletiva, de uma instância legítima capaz de opor ao sentimento de alienação uma "crença" nova, apta a instituir uma comunidade.

\section{0 estrangeiro como protótipo}

Tal função foi assumida no século XIX pela nação. Os Estados europeus, que já haviam se desenvolvido, por meio da monopolização do uso da força, como instância superior de repressão e ordem nos séculos XVI e XVII, ascenderam adicionalmente, no curso da formação do Estado nacional, a instâncias de integração e atribuição de sentido, fornecendo aos seus cidadãos uma fonte de identidade - na forma de uma comunidade nacional - em troca dos tributos da lealdade política (no âmbito externo) e do reconhecimento da autoridade estatal (âmbito interno). Os aspectos comuns da língua, do ethos e da procedência tomaram o lugar da religião como indicadores para a inclusão do indivíduo no conjunto da sociedade (cf. Nassehi 1990: 264). Na medida em que escondia desigualdades reais de remuneração, de profissão e de influência política entre os membros da sociedade - declarados não obstante como de igual valor -, a unidade nacional assim instituída se tornou, por sua vez, religiāo; e o Estado se tornou a nova "crença da modernidade" (cf. Hahn 1993: 197). É a essa ficção consensual dos Estados nacionais modernos que fizeram (e fazem) referência as definiçōes subsequentes de alteridade. $\mathrm{O}$ estrangeiro em território nacional tornou-se o protótipo do outro (cf. Hahn 1994: 163), e a obtenção da cidadania tornou-se o princípio do pertencimento à comunidade nacional. Ao mesmo tempo, o não pertencimento ganhou o status de um estigma sistemático, cuja su- peração se tornou o objetivo político maior de seus portadores. A exclusão que era preciso combater era a contraparte da inclusão a ser concedida por meio da cidadania:

\begin{abstract}
"Aqueles que não eram cidadãos do Estado haviam se tornado estrangeiros por definição [...] A história do século XIX (e de fato também a do $X X$ ) tem sido a de que alguns (aqueles com privilégios e vantagens) têm tentado definir a cidadania de modo estreito, enquanto todos os outros têm procurado validar uma definição mais ampla. É em torno dessa luta que se centrou a teorização intelectual dos duzentos anos seguintes. É em torno dessa luta que os movimentos sociais foram formados" (Wallerstein 2003: 651).
\end{abstract}

O monopólio do Estado nacional moderno com relação ao uso da força exerceu, assim, não só uma função de proteção da vida e da propriedade dos cidadãos, mas dispôs além disso de um poder de definição que determinava os critérios de pertencimento à comunidade nacional e legitimou, dessa forma, a coerção contra os não cidadãos. Estranhos não eram mais apenas os inimigos (do Estado), mas especialmente aqueles que se opunham aos critérios estabelecidos e, com isso, colocavam em questão o caráter autoevidente do princípio nacional. Para a modernidade das nações vale, então, que:

mesmo inimigos [...], dito de forma um pouco exagerada, são em certo sentido menos ameaçadores que os estrangeiros, porque eles obedecem à ordem estabelecida dos estereótipos do que é próprio e do que é do outro [...] Os estrangeiros são a pura comprovação de que o caráter 'natural' da ordem local é fruto de convençōes, algo artificial. Por meio da contradição neles corporificada, eles demonstram continuamente que o mundo poderia ser diferente (Beck 1995: 140).

Com isso, a promessa da inclusão completa foi "cumprida", mas de maneira paradoxal: a participação (concedida pelo Estado) na identidade cultural homogênea tinha como pressuposto o mandato estatal para a pacificação do ambiente 
social interno - uma "licença" que, no entanto, comumente vinha acompanhada da exclusão dos "outros" culturais pelo uso da força. Sobre o pano de fundo da sistemática "invenção do outro" (Castro-Gómez 2000) no curso da produção e manutenção da ordem social racional, que a modernidade havia se colocado como tarefa, estratégias de discriminação aparecem como o reverso do "projeto da modernidade" (Habermas 1990) - e, portanto, são tão constitutivas dessa época histórica quanto os seus objetivos declarados.

A classificação institucionalizada pelo Estado nacional entre nativos e estrangeiros, entre cidadãos e "outros", apesar de elevada rapidamente ao posto de mecanismo principal de alocação de identidade social, foi apenas a expressão da ideia fundamental - característica da modernidade - da dominação da natureza por meio da construção da ordem. No projeto de Francis Bacon de subjugação da natureza com a ajuda da ciência e da técnica, no programa cartesiano de fazer dos homens maîtres et possesseurs de la nature ("senhores e possuidores da natureza", Descartes 1997: 62), assim como no Estado hobbesiano monopolizador da coerção física como solução para a originária "guerra de todos contra todos" - em todos esses casos, um "ordenamento direcionado a fins" (Bauman 1992: 28) valia como a antítese da "natureza" sem finalidades e, por isso, irracional. Analogamente, a nova autodefinição dominante dos Estados modernos - a nação - deveria servir para superar o "estado de natureza" e substituí-lo pela "natureza" fictícia da comunidade nacional (cf. Hahn 2000: 57). Este desenvolvimento baseado no aumento do domínio sobre a natureza externa e interna - e que Max Weber descreveu como racionalização progressiva, Norbert Elias como processo civilizatório e Michel Foucault como processo de disciplinarização - mirava, no contexto do Estado nacional, a produção de um sujeito de direito que obedecesse aos limites constitucionais previamente formulados e que pudesse assumir um papel produtivo na realização e manutenção do projeto nacional.
O otimismo da filosofia iluminista com relação ao progresso funcionou como base legitimadora para a transformação empírica da natureza externa, a partir da qual a ciência esperava, desde Bacon, a melhora contínua das condiçōes de vida (cf. Bonß 2002: 121). Sobre esse mesmo fundamento, o princípio de assimilação pertencente à práxis moderna foi também elevado a norma: os desvios com relação à norma jurídico-política - e com isso toda forma de ser diferente do sujeito de direito - foram deslegitimados como perturbaçōes na ordem social a ser produzida, e a assimilação da diferença, ao contrário, foi considerada como a emancipação da comunidade social com relação ao estado de natureza. Segundo Zygmunt Bauman, a assimilação foi

\begin{abstract}
[... um de muitos detalhes no plano geral da substituição da ordem natural das coisas por uma artificialmente construída; e foi uma tentativa da parte daqueles que a construíram de exercer um direito monopolista de separar os 'adequados' dos 'inadequados', os 'dignos' dos 'indignos', e de formular as condições sob as quais seria possível uma passagem da segunda categoria para a primeira (Bauman 1991: 38 e ss.).
\end{abstract}

Em outras palavras: foi o caráter questionável (imprescindível em uma época de ideologia universalista) das desigualdades existentes há muito tempo - sejam elas baseadas na instrução, sexo, idade, pertencimento étnico ou raça - que tornou necessária a sua tradução em categorias binárias rígidas, já que "naturalizadas". Com base nisso, consequentemente, tanto a exclusão quanto a inclusão foram justificadas a partir do seu caráter natural; a distinção entre "civilizado" e "bárbaro", constitutiva da autocompreensão europeia, funcionou como o modelo para tanto.

\section{Bases da discriminação global no longo século XIX}

A homogeneização das identidades nacionais na Europa no século XIX foi acompanhada pela agressiva política imperialista das potências colo- 
niais e pela legitimação científica da civilização europeia como "o centro e o fim" (Hegel 1955: 235) do Velho Mundo. Partes do mundo já colonizadas ou ainda por conquistar foram, em conexão com isso, definidas como "o outro" da Europa e da modernidade. Essa experiência fundamental de alteridade da modernidade tardia (sobre cuja base a identidade europeia ocidental se associou às noçōes de civilização, racionalidade, cientificidade, progresso e ausência de violência, e a alteridade não europeia, por contraste, representava a categoria restante, impregnada de barbárie, irracionalidade, superstição, atraso e violência) fornecia a base para a visão dualista de mundo da qual iriam se servir, subsequentemente, tanto as ciências (sociais) modernas quanto os conceitos de cidadania. A lógica econômica ligada à "missão civilizatória" consistiu na necessidade de estabelecer, no contexto da economia capitalista mundial que se estruturava crescentemente nos centros (coloniais) e nas periferias (colonizadas) (cf. Wallerstein 1974), hierarquias relativas ao valor do trabalho realizado, com a ajuda das quais tanto os custos da integração "do outro" quanto os direitos a ele concedidos puderam ser mantidos os mínimos possíveis. Enquanto o projeto de formação da identidade dos Estados nacionais modernos tinha como objetivo uma disciplinarização e normalização (voltadas para dentro) dos sujeitos de direito, a sua habilidosa expansão econômica (voltada para fora) representava o promotor correspondente de alteridade (cf. Boatcă /Neudecker 2006, Boatcă 2009).

As consequências da Revolução Francesa em termos de políticas nacionais foram paradigmáticas para as práticas discriminatórias que foram institucionalizadas sobre essa base. Em conexão direta com a revolução, os súditos do recém-proclamado Estado nacional francês foram classificados como "cidadãos ativos" ou "passivos" (cf. Hanagan
2002: 167). A primeira categoria compreendia principalmente homens proprietários, que "trocavam" o tributo militar do serviço compulsório de defesa e o tributo econômico do imposto por direitos civis; a segunda categoria contava com as mulheres, os estrangeiros e as crianças, bem como todos os que não tomavam parte na configuração da vida pública (cf. Siéyès, in: Wallerstein 2003: 651 e ss.). As mulheres, definidas ademais como necessitando de proteção e próximas de um estado natural (por conta da exclusão do serviço militar e do atributo da capacidade de gerar filhos), encontravam-se fora dos domínios masculinos da cultura associados à participação política, ao trabalho assalariado e às funções de proteção e provisão (cf. Boatcă 2003: 67). O modelo burguês de família propagado pelo Estado, no qual às mulheres correspondia exclusivamente 0 papel de dona de casa e mãe, vinculava assim a invenção da produção de subsistência à sua estigmatização como "não trabalho"2 e também a uma "licença territorial para o uso da força no contexto doméstico" (Taylor 2000: 555), que correspondia ao monopólio estatal da coerção física no campo nacional. À luz do fato de que o "castigo" de mulheres (esposas) teve validade legal até meados do século XX, não é de se admirar que a violência doméstica tenha tomado a forma da violência masculina contra as mulheres.

A negação de direitos civis ativos a trabalhadores simples por conta de sua ausência de propriedades e de instrução - ausência que "comprova" sua falta de interesse na preservação da ordem social (cf. Wallerstein 2003: 662) - e a exclusão dos negros e mulatos da comunidade dos cidadãos franceses na colônia de Saint-Domingue refletiam também os demais critérios com base nos quais as classificaçōes do século XIX seriam levadas a cabo em todo o espaço fora da Europa. O sexo, a raça e o status de proprietário, assim como a ca-

\footnotetext{
2 Esse fenômeno - inicialmente limitado às mulheres das camadas burguesas - da definiçăo interna ao campo da natureza, que Maria Mies (1996) descreve como "feminização da casa", foi gradualmente expandido para as mulheres da pequena burguesia, e mais tarde também para as proletárias. Cf. sobre isso também von Werlhof et al. 1983, Mies 1996: 103.
} 
pacidade de ler e escrever, formavam aí, segundo normas europeias, as bases para a obtenção da cidadania e, ao mesmo tempo, para a construção das figuras do outro que serviam como folha de contraste para a identidade moderna.

As tipologias assim consolidadas legitimaram o estabelecimento de uma escala hierárquica para a remuneração das atividades de trabalho, de acordo com o grau da proximidade com relação ao perfil de cidadania sustentado por mecanismos institucionais. Dessa forma, o trabalho dos negros e dos índios nas colônias, assim como o das mulheres e das crianças na economia mundial como um todo, foi tratado como de menor valor - e o das donas de casa até como "não trabalho" (von Werlhof et al. 1983). A tarefa de sancionar e reproduzir o modelo ocidental de cidadania foi assumida - como na própria Europa ocidental - pelas constituiçōes nacionais, escolas, hospitais e prisōes. De forma correspondente, deficientes físicos, homossexuais e dissidentes ficam fora do quadro estabelecido do sujeito de direito economicamente lucrativo $e$ socialmente conformado tanto quanto as mulheres, os analfabetos, os não brancos ou escravos - como documenta Santiago Castro-Gómez em relação à América Latina do século XIX:

A obtenção da cidadania é [...] um filtro pelo qual só passarão aquelas pessoas cujo perfil se ajuste ao tipo de sujeito requerido pelo projeto da modernidade: homem, branco, pai de família, católico, proprietário, letrado e heterossexual. Os indivíduos que não cumprem esses requisitos (mulheres, empregados, loucos, analfabetos, negros, hereges, escravos, índios, homossexuais, dissidentes) permanecerão fora da 'cidade letrada', reclusos no âmbito da ilegalidade, submetidos ao castigo e à terapia por parte de mesma lei que os exclui (Castro-Gómez 2000: 149).

\section{Estratégias locais de discriminação no século XXI}

A discriminação atual de migrantes e minorias étnicas segue a mesma lógica de inclusão/ex- clusão que conecta o projeto de formação de identidade dos Estados nacionais modernos à patologização dos sujeitos (de direito) nas colônias fora da Europa. Como tal, ela representa um problema estrutural, com diversas manifestaçōes, de um sistema-mundo que é ao mesmo tempo moderno e colonial (cf. Mignolo 2000), manifestaçōes que se articulam geralmente, dependendo do contexto, como racismo cultural ou como xenofobia de fundamento étnico ou religioso. Com isso, a postura distinta (em termos socioculturais e programático-políticos) de Estados nacionais face à sua própria posição como "país de imigração" afeta decisivamente - apesar da globalização e da alardeada intenção de uma política transnacional - o tratamento com relação aos migrantes e às minorias étnicas.

\subsection{EUA: o melting pot desigual}

Nos Estados Unidos, onde o caráter de país de imigração faz parte da autocompreensão nacional, é a distinção entre a origem europeia ou não europeia que funciona como o eixo da discriminação racial de migrantes (Grosfoguel/Georas 2000). Enquanto que grupos de migrantes europeus como irlandeses, italianos e europeus do leste - e também australianos, africanos e sul-americanos de origem europeia - foram classificados no contexto da hierarquia racial como "brancos", os migrantes da América Latina e do Caribe ingressaram na sociedade norte-americana na maioria dos casos unicamente como "negros" - ou como uma gradação disso (Ignatiev 1995, Goldberg et al. 2006). Nesse contexto, a categoria "latino" (assim como o etnônimo "hispânico ou latino", introduzido oficialmente no censo populacional desde 1997) não designa um grupo populacional homogêneo. Ao contrário: essa categoria, baseada na auto-avaliação, é composta de pessoas que migraram para os EUA em diferentes momentos e a partir de distintos países de língua espanhola, assim como daqueles que, em consequência da guerra mexicano-americana, se tornaram automaticamente moradores dos EUA 
(Grosfoguel/Maldonado-Torres/Saldívar 2005: 6). Dependendo do seu uso, a designação hispânico/latino compreende também, contudo, pessoas de origem brasileira ou portuguesa, a população indígena da América do Norte e Central ou os latino-americanos com origem na África negra (os "afro-latinos"). O discurso da diferença racial, cunhado na correlação colonial de forças entre os imigrantes europeus "brancos" de um lado e os "negros" ou "pardos" (nativos norte-americanos, escravos africanos e moradores de regiōes colonizadas do México, Porto Rico e Filipinas) de outro, é extrapolado, no caso dos "latinos", para grupos populacionais que, em consequência de intervençōes militares diretas ou indiretas do governo dos EUA nos seus países de origem, imigraram para os Estados Unidos (cf. Grosfoguel 2003). Dessa forma, dominicanos, salvadorenhos, ou guatemaltecas nos EUA são, por força da analogia com os chicanos e porto-riquenhos, comumente construídos e racializados como "negros" - ou, para todos os efeitos, como "não brancos".

O exemplo dos imigrantes cubanos representa, nesse contexto, uma exceção que torna ainda mais claro o caráter instrumental das práticas de discriminação. Como parte do Programa de Refugiados Cubanos do Ministério da Saúde, Educação e Assistência Social dos Estados Unidos, os cubanos exilados beneficiaram-se entre 1960 e 1980 de ajuda social, cursos bilíngues de idiomas, subsídios para a qualificação profissional, empréstimos estudantis e seguros de saúde subvencionados - o que, no contexto de política externa dos EUA durante a Guerra Fria, serviu para demonstrar a superioridade do modelo capitalista em face do socialista (PedrazaBailey 1985, Grosfoguel 1997). A origem não europeia dos migrantes cubanos, que nos demais casos funcionava como base para a racialização dos "latinos", ficou aqui obscurecida no discurso público, e o contexto político de origem, ao contrário, foi instrumentalizado como explicação para a insuficiente mobilidade vertical dos cubanos em sua terra natal e para a bem-sucedida ascen- são social e econômica nos EUA. Com isso, os imigrantes cubanos alinham-se entre os (poucos) grupos de migrantes cuja experiência (histórica e politicamente) contingente fornece a base para que sejam generalizados os mitos do melting pot não discriminatório e do sonho americano, ao mesmo tempo em que é encoberta a "genealogia colonial" dos regimes atuais de migração (Gutiérrez-Rodríguez 2005).

Esse é o caso dos migrantes vindos da Coreia, de Cuba, Hong Kong e Taiwan. Ao criar um estrato médio de 'grupos minoritários bem-sucedidos' (minorias-modelo), os grupos brancos euro-americanos dominantes podem criar vitrines simbólicas raciais/étnicas para escapar à crítica de discriminação racial feita pelos imigrantes coloniais e pelos sujeitos coloniais/raciais do império. Isso contribui para a invisibilidade da discriminação racial que ainda persiste nos Estados Unidos (Grosfoguel/Maldonado-Torres/Saldívar 2005: 12).

A ausência de uma contextualização do pano de fundo histórico e político dos distintos grupos de migrantes faz com que o sucesso da integração de imigrantes mexicanos ilegais ou da minoria porto-riquenha, que raramente usufruem do apoio estatal, seja comparado ao dos refugiados provindos de Estados adversários dos EUA (Cuba, Nicarágua, Vietnam), que experimentam um tratamento adequado por parte das autoridades e cujo ingresso bem-sucedido no país é visto positivamente. O sucesso da integração é então atribuído somente à disciplina, ao ethos profissional ou no máximo ao capital social de cada grupo étnico, enquanto que as desigualdades no tratamento estatal com relação aos migrantes são concebidas como parte de uma política nacional de imigração na qual não exercem qualquer papel nem o passado colonial, nem as relaçōes políticas e econômicas atuais entre os países de origem e de destino dos migrantes. No entanto, é hoje tão apropriado quanto no tempo da Guerra Fria afirmar que os Estados não são atores autônomos, mas estão imbricados em estruturas supranacionais de poder que refletem as relaçōes 
econômicas e políticas de hierarquia do sistema capitalista global. O respectivo pano de fundo geopolítico é, portanto, central para uma análise diferenciada da situação dos migrantes e de "outros etnicizados" nos EUA de hoje, bem como em outros contextos (pós-)coloniais:

\begin{abstract}
[...] é crucial localizar cada grupo étnico-racial no contexto mais amplo das relações centro-periferia entre o seu Estado de origem e os EUA. [...] É significativo, aqui, se a relação centro-periferia é colonial ou neocolonial com uma intervenção militar ativa por parte dos EUA, ou periférica com pouca ou nenhuma importância geopolítica para os Estados centrais. Da mesma forma, a origem de classe e o histórico educacional dos migrantes, bem como a sua percepção pública, afetará as políticas americanas com respeito à recepção dos migrantes e, subsequentemente, os modos de sua incorporação no mercado de trabalho (Goldberg et al. 2006: 267).
\end{abstract}

O obscurecimento do contexto histórico-cultural da migração e a reprodução de mecanismos discriminatórios, ligada a tal obscurecimento, têm como sintoma o fato de que os cubanos são até hoje destacados com "os latinos bons, aplicados", que - em contraste com a população latino - e afro-americana dos EUA, geralmente não instruída, pobre e fortemente criminalizada - são considerados "brancos". Tais diferenças no tratamento dos migrantes provindos da América Latina foram em grande parte obscurecidas depois do 11 de setembro de 2001, na medida em que, por meio das medidas de segurança nacional cada vez mais rígidas e do racial profiling, não só árabes-americanos e pessoas oriundas do sul da Ásia, mas também a população hispano-americana foi colocada sob uma suspeita geral de terrorismo (cf. Jonas 2006: 6 e ss.). Assim, muitas das medidas para a luta contra o terrorismo contidas no USA Patriot Act de 2001 eram partes de leis de imigração mais antigas: tanto o Illegal Immigrant Reform and Immigrant Responsibility Act, que previa o encarceramento preventivo de imigrantes infratores e a facilitação da deporta- ção, quanto o Anti-Terrorism and Effective Penalty Death Act, que permitia a prisão retroativa de migrantes por ofensas e delitos menores, assim como o Welfare Reform Act, que negava o acesso de todos os não cidadãos à assistência médica pública e à formação escolar, haviam contribuído já em 1996 para uma criminalização intensificada de imigrantes tanto legais quanto ilegais. No contexto dos ataques de 11 de setembro, as leis já existentes permitiram a redefinição da população migrante em seu conjunto como ameaça terrorista e legitimaram, por meio disso, medidas repressivas - da prisão provisória até a extradição sumária - cujos obstáculos encontrados no direito penal em vigor puderam ser suspensos de última hora:

Em nome da 'segurança nacional' - mesmo que tendo como base, na prática, violações de leis de imigração (visto) sem qualquer relação com o terrorismo -, vários milhares de migrantes latinos foram sujeitos a apreensões arbitrárias, detenção preventiva e/ou deportação sumária, sem qualquer recurso a assistência jurídica ou a cortes de apelaçāo. O governo dos EUA utilizou amplamente os dispositivos anti-imigrantes das Anti-Terrorist Laws $(1996,2001)$ em parte porque o direito de imigração não garante os devidos direitos de processo que estão disponíveis para cidadãos sob o direito penal (Jonas 2006: 9).

Pelo menos desde os protestos de massa de 2006 contra a nova lei de imigração do governo Bush e a militarização, a ela ligada, da fronteira com o México, os imigrantes latino-americanos gozam, entre os grupos de imigrantes nos EUA, da maior visibilidade internacional. Internamente, a sua visibilidade tem, entretanto, uma conotação em geral negativa e é estreitamente vinculada à sua categorização como "não brancos": segundo o relatório do Federal Bureau of Justice Estatistics (citado em: Robinson 2007), é de fato igual a probabilidade de que brancos, afro-americanos e latino-americanos sejam submetidos a um controle de trânsito sem relação com algum tipo de suspeita; motoristas negros são, no entanto, 
detidos duas vezes mais que os brancos, os carros de negros e latino-americanos são mais que duas vezes mais revistados que os dos brancos, enquanto os latino-americanos recebem multas de trânsito mais frequentemente que brancos $e$ negros. Isso significa, em vista do racial profiling, que o espectro do comportamento criminalizado se ampliou do "dirigir sendo negro" para "dirigir sendo pardo". Em vista do forte crescimento da população latino-americana nos EUA nas três últimas décadas, bem como de sua migração interna para estados que têm o inglês como língua única e que são marcados por uma classe média tradicionalmente "branca", onde os não brancos estão sujeitos a uma intensidade de perseguição mais de dez vezes maior do que a dos "habitantes locais" (cf. Mucchetti 2005), prefigura-se o fortalecimento de uma cultura de discriminação que continua a fazer uso da retórica do conflito de raças (cf. sobre isso também Boatcă/ Neudecker 2006).

\subsection{Alemanha: um país de imigração contra a vontade}

Na Alemanha, por sua vez, onde por muito tempo tanto o discurso político quanto o científico evitaram a designação "país de imigração" e onde o conceito de "raça" permanece, por conta do passado nacional-socialista, sub-tematizado e sub-teorizado, ${ }^{3}$ uma dimensão central da discriminação se dá até hoje ao longo do eixo que distingue nativos versus estrangeiros. Designaçōes correntes como "política de estrangeiros", a "questão dos estrangeiros" e "hostilidade contra estrangeiros" (xenofobia), que têm como função dar nome a áreas problemáticas importantes de uma sociedade majoritária alemã com minorias étnicas, contribuem, por meio da dicotomização da diferença entre o que é próprio e o que é do outro, para deixar de fora das considerações o contexto social e histórico da imigração como processo (cf. Geißler/Meyer 2008: 232 e ss.); suas consequências reforçam, além disso, uma figura do estrangeiro que é homogeneizada e construída como o polo oposto ao habitante nativo. Essa figura traz com isso não apenas o estigma do ser-outro ético, mas também o do ser cultural e normativamente carente, ao qual, como no caso dos migrantes racializados nos EUA, é atribuída (por meio da discrepância linguística com relação à norma social majoritária - discrepância interpretada como uma falta de competência em lugar de uma qualificação adicional) uma tendência geral para o desvio e, assim, para a criminalidade.

Para a maioria dos meios de comunicação de massa alemães, o clichê do "estrangeiro criminoso" - ocupado inequivocamente por homens - é desde muito tempo "a faceta dominante da imagem do estrangeiro" (Geißler/Meyer 2008: 348), assim como a porcentagem comparativamente maior de estrangeiros na prática de crimes na Alemanha é um dos preconceitos mais persistentes. De fato, no discurso público (sobretudo policial) de criminalização, diversos conjuntos temáticos são classificados a partir de meados da década de 1980 como "o problema dos estrangeiros" - desde as campanhas contra as drogas, passando pelo crime organizado, até, recentemente, a "perda de segurança" depois da abertura das fronteiras na Europa ocidental. Nesse discurso, entretanto, trata-se essencialmente sempre da produção de uma ordem (nacional-estatal) - e da demanda por um controle social mais intensivo, especialmente após o 11 de setembro - e sua tônica é o medo (fomentado politicamente e pelos meios de comunicação de massa). O temor geral da população com relação à criminalidade, cujo processo é subjetivo

\footnotetext{
${ }^{3}$ Exceçōes, como se sabe, confirmam a regra. Para novas análises críticas acerca de raça e racismo tanto no contexto alemāo quanto em uma perspectiva comparada, cf. Costa 2007, Ha 2007, Dietze et al. 2009. Apesar de nesse meio tempo a discussāo sobre o racismo ter passado a desfrutar de um vivo interesse também na Alemanha, isso não vale para o conceito de "raça", que em textos de língua alemā ainda é colocado entre aspas ou supostamente distanciado de suas conotaçōes nazistas com ajuda do termo inglês race. Com isso surge a situaçāo paradoxal na qual fenômenos percebidos de maneira aguda, como o racismo, e processos sociais como a racializaçāo se dão aparentemente sem objeto, pois a sua categoria fundamental permanece inominável.
} 
e independente da criminalidade violenta que ocorre factualmente (cf. Lamnek 2000: 255), é, no caso da criminalidade cometida por estrangeiros, potencializado pelo medo "do" estrangeiro como o outro cultural e confirmado por uma cobertura midiática "orientada por acontecimentos" (Butterwegge 2002: 6), isto é, que não presta atenção aos quadros estruturais:

Na medida em que os meios de comunicação de massa tematizam ambos os problemas (estrangeiros e criminalidade) de um só fôlego, compreende-se facilmente a preocupação com o tema da violência. O que é fatal é que os estrangeiros, que em grande medida são vítimas de violência por parte de alemães, se encontram implicitamente em um novo papel: a luta contra a violência se torna uma luta contra os estrangeiros, apesar de, nas açōes violentas que causaram especial alvoroço nas emoçōes da opinião pública, os estrangeiros terem sido as vítimas da violência (Albrecht 2001: 24).

A partir do problema da imigração, ao qual parte da população (verificavelmente) alemã reagiu com rejeição, discriminação e tumultos violentos, surgiu o "problema do imigrante". De forma semelhante a como acontece nos EUA, aparecem assim estratégias de discriminação aplicadas com base no contraste construído entre a integração bem-sucedida, de um lado, e a criminalidade que coloca a ordem em risco, de outro: na estatística criminal da polícia (polizeiliche Kriminalstatistik, abreviado como PKS), os dados acerca dos suspeitos de crimes que vieram a conhecimento público foram coletados separadamente de 1953 a 2001 entre "alemães" e "não alemães", sem diferenciar, contudo, entre a população que mora na Alemanha - à qual pertencem também migrantes na terceira geração ou aqueles com dupla cidadania - e as pessoas vivendo temporariamente no país - imigrantes ilegais, mão de obra estrangeira, pessoas de passagem para outros destinos, candidatos a asilo político, pessoas que viajam diariamente ao país a trabalho, turistas etc. Somente a partir de 2001 foram incorporados no
PKS, no caso dos estados da Baviera e da Baixa Saxônia, os dados sobre a duração da permanência de suspeitos não alemães no país (BKA 2001: 124); desde 2002 foram elencadas para todo o país também informaçōes diferenciadas para a distribuição dos suspeitos não alemães de acordo com o motivo da estadia.

O fato de que o PKS contém o número de suspeitos, e não o número de criminosos - isto é, somente são coletados, para cada ano do relatório, os dados de pessoas que foram investigadas (cf. BKA 2008: 10) - é algo que faz os números pesarem muito para o lado dos estrangeiros, quando se considera que eles estão sujeitos a uma intensidade mais alta de perseguição e se tornam suspeitos aos olhos policiais com mais frequência, por conta de sua estrutura social, de idade e de sexo: em segmentos multiétnicos encontram-se, a saber, mais pessoas do sexo masculino, mais jovens e poucos idosos; além disso, eles moram mais frequentemente em grandes cidades, onde está disponível uma estrutura mais ampla de oportunidades para a prática de delitos, e pertencem comumente às camadas sociais periféricas (cf. BKA 2008: 105). Somam-se a isso os delitos específicos de estrangeiros, como violaçōes das leis de estrangeiros ou dos procedimentos de asilo, ou a lei de livre movimentação de cidadãos da União Europeia, as quais, por definição, não podem ser cometidas por alemães e nas quais os não cidadãos estão, em contraste, sobrerrepresentados. Com isso, a porcentagem dos suspeitos não alemães caiu em 2008, quando as infraçōes específicas de estrangeiros não são contabilizadas, de $96 \%$ para 18,9\% do total (cf. BKA 2008: 105). Levando em consideração os efeitos regionais, de idade e de camada social dos segmentos multiétnicos, a porção dos estrangeiros no conjunto total da criminalidade se reduz de tal forma que, finalmente, os 9\% de "não alemães" na população alemã violam a lei de maneira proporcionalmente menos frequente (cf. Geißler 2001: 29). Não obstante, o estereótipo do "estrangeiro criminoso" é um indicador importante do temor 
geral da população e, como tal, um elemento inerente ao discurso de segurança e de ordem. ${ }^{4}$

Atribuiçōes e marginalizações favorecidas pelo uso da linguagem são transferidas da consciência pública para a ação, que ocorre tanto no nível individual quanto no institucional. Esse processo de eliminação social do "outro" e, ao mesmo tempo, delimitação social do "próprio" é promovido pelos meios de comunicação como o "definidor primário" e a peça que conecta o racismo institucional, o pseudocientífico e o cotidiano (cf. Butterwegge 2002), e isso por meio de cenários ameaçadores sobre cartéis de drogas, guerras entre gangues, fraude em concessōes de asilo, tráfico de seres humanos - e recentemente, de novo, sobre terrorismo. Uma pesquisa de análise de discurso envolvendo seis meios de comunicação impressos de alta circulação em um período de três meses obteve o resultado de que a cobertura acerca de criminosos estrangeiros se distingue marcadamente da cobertura sobre os de origem alemã (cf. Jäger et al. 1998). Enquanto nos artigos acerca de "nativos" a nacionalidade não é mencionada e a proteção pessoal é garantida por meio da utilização das iniciais do nome seguidas da profissão e da idade, são elementos constantes nas notícias sobre criminosos estrangeiros a referência à nacionalidade, à origem e à (falta de) conhecimento da língua alemã - e são mostradas também frequentemente fotos, que comprovam a aparência "estrangeira". No caso dos infratores alemães, são examinados os motivos para o ato e a estratégia de ressocialização é trazida para a discussão; no caso dos crimes - representados sem mais como muito mais brutais e perigosos - de infratores estrangeiros (cuja delinquência múltipla é especialmente enfatizada e vinculada à expansão do crime organizado), é em geral a perspectiva da polícia e do tribunal, e não a "do" criminoso, que é levada em consideração.

Críticos desse tratamento diferenciado e discriminador, que se dá pela utilização simultânea de uma terminologia indiferenciada, enfatizaram por isso repetidamente que o conceito de estrangeiro reúne

[...] somente uma parcela cada vez menor do segmento multiétnico; estatísticas e estudos sobre estrangeiros descrevem sempre insuficientemente as quantidades e ocorrências efetivas no segmento multiétnico. O conceito de estrangeiro é um modelo obsoleto, ultrapassado pela realidade social. Além disso, conotaçōes secundárias, em parte etnocêntricas e inibidoras da integração, aderem ao conceito de estrangeiro: ele acentua o caráter de algo estranho e um status legal mais baixo, enfatiza fortemente o 'não pertencente', o 'excludente' (Geißler/Meyer 2008: 233).

Certamente não são apenas as conotaçōes secundárias do conceito oficial e sociológico de "estrangeiro" que em grande medida inibem a integração, mas também, e especialmente, os efeitos discriminatórios e reforçadores de hierarquia do próprio conceito de "integração": a Alemanha se tornou desde a década de 1960 um país de imigração, seja para trabalhadores, pessoas de origem alemã morando em outros países que retornam (tardiamente) à Alemanha, refugiados ou imigrantes ilegais; mas esse fato esteve durante muito tempo em contradição com a ausência de uma política coerente de integração e de um engajamento sistemático relativo aos problemas de integração que surgiram. A postura atual de um "país de imigração contra a vontade" (Geißler/ Meyer 2008: 237), por outro lado, se faz sentir em uma política de integração que é concebida como uma obrigação educacional e de formação para imigrados e que vincula, assim, as relaçōes dominantes e práticas discriminatórias a um nível

\footnotetext{
${ }^{4}$ Um exame crítico dos números do PKS nāo pode, naturalmente, subestimar a criminalidade factual da população estrangeira. À descoberta, por exemplo, de que os migrantes a trabalho sāo claramente mais fieis às leis que os alemāes com um perfil social comparável (cf. Geißler/Meyer 2008: 348), se contrapōem resultados que indicam um grande aumento da criminalidade entre jovens migrantes desde a metade da década de 1990 (Pfeiffer/Wetzels 2001 ). Utilizar, em lugar da nacionalidade, o perfil social como critério de ordenamento permitiria, entretanto, uma apreensão diferenciada do desenvolvimento da criminalidade.
} 
de nacionalização (cf. Gutiérrez-Rodríguez 2003: 161 e ss.; Ha 2009: 138). Uma política que declara cursos de integração como compulsórios somente para os cidadãos de países de fora da Uniāo Europeia e que prevê sançōes negativas somente para estes - sançōes que podem, no caso de "vontade insuficiente de integração", ir da recusa da cidadania até a deportação - faz do pertencimento à União Europeia um critério de diferenciação e discriminação que distingue sistematicamente, como no caso dos "bons" e dos "maus" latinos nos EUA, os "bons" dos "maus" migrantes na União Europeia:

Na medida em que se fala compulsivamente acerca da necessidade de integração unilateral do outro, a integração pode ser instrumentalizada como uma profissão de fé publicamente celebrada da própria boa vontade, do caráter aberto da sociedade alemã e da superioridade das democracias ocidentais. Ao mesmo tempo, realidades sociais como o racismo estrutural, discriminaçōes institucionais e exclusões socioculturais, disseminadas pela sociedade alemã, aparecem no (dis) curso oficial de integração como pouco relevantes [...] Desigualdades sociais e exclusōes são banalizadas, por fim, como pequenos mal-entendidos, que teriam sua causa no conhecimento insuficiente dos imigrados com relação à língua alemã. (Ha 2009: 141).

A patologização, daí resultante, dos imigrantes indesejados como corpos estranhos que necessitam de integração em um todo nacional homogêneo se serve, dessa maneira, do mesmo imaginário das práticas coloniais dos séculos XIX e XX, que construíram os sujeitos coloniais como criminosos e infantis por "natureza" $e$, desse modo, como carecendo de civilização e correção. O direito de cidadania alemão, que é orientado primariamente de acordo com o princípio de descendência, representa nesse sentido uma tentativa de preservar o caráter nacional na medida em que se considera os processos de imigração como pontuais no tempo e insignificantes em quantidade - em contraste com a população nativa, temporalmente duradoura $e$ numericamente dominante. O "modelo de opção" para filhos de migrantes existente desde 2000 e baseado no princípio territorial não altera em nada a situação, pois ele os obriga em última instância a decidir por uma única cidadania $e$, com isso, fortalece novamente a ideia de lealdade a um Estado nacional. A complexa situação da imigração na Alemanha unificada é apreendida de forma insuficiente pela maioria das estatísticas oficiais de população, as quais, como a estatística criminal da polícia (PKS), utilizam a classificação de acordo com a cidadania: tais estatísticas escamoteiam, por exemplo, os distintos contextos de migração e de recepção das várias geraçōes de pessoas com origem alemã vivendo no estrangeiro que obtiveram a cidadania ao ingressarem na República Federal, e não chegam a tematizar, por sua vez, tais contextos no caso dos migrantes a trabalho e dos refugiados. Quando não se leva isso em consideração, o resultado não é apenas a cegueira histórica com relação aos movimentos pós-coloniais de migração e às transformaçōes (política e economicamente motivadas) nos regimes de imigração e na política do mercado de trabalho, mas também uma reprodução sistemática da dicotomização "estrangeiros versus nativos", renovada a cada geração.

É preciso atentar, portanto, nos exemplos aqui discutidos dos EUA e da Alemanha - e também em todas as sociedades de imigração -, para o fato de que os imigrantes nunca chegam a um território nacional neutro, sem história, mas ingressam geralmente em espaços metropolitanos "que já estão contaminados por uma história colonial, um imaginário colonial, conhecimentos coloniais, uma hierarquia racial/étnica ligada a uma história de império" (Grosfoguel/MaldonadoTorres/Saldívar 2005: 8). A imbricação de estratégias globais e locais de discriminação requer, por conseguinte, uma perspectiva histórica de análise que permita considerar a função e as características estruturais da lógica moderna de inclusāo/ exclusão como um sistema que institucionaliza a demanda do universalismo na mesma medida 
em que universalizou instituiçōes para a sua sistemática obstrução.

Tradução do alemão: Mariana O. N. Teixeira

Diskriminierung in der longue durée. Globale Muster und lokale Strategien, em: Ulrike Hormel/Albert Scherr (comp.): Diskriminierung. Grundlagen und Forschungsergebnisse, Wiesbaden: VS-Verlag, pp. 115-133

\section{Bibliografia}

Albrecht, G. 2001. Einleitung: Gewaltkriminalität zwischen Mythos und Realität. In: ebd. (Hrsg.): Gewaltkriminalität zwischen Mythos und Realität. Frankfurt, S. 9-67

Bauman, Z. 1991. Moderne und Ambivalenz, in: Bielefeld, Uli (Hrsg.): Das Eigene und das Fremde: neuer Rassismus in der alten Welt? Hamburg, S. 23-49

Bauman, Z. 1992. Moderne und Ambivalenz. Das Ende der Eindeutigkeit, Hamburg

Beck, U. 1995. Wie aus Nachbarn Juden werden. Zur politischen Konstruktion des Fremden in der refl exiven Moderne. In: Ders.: Die feindlose Demokratie. Ausgewählte Aufsätze. Stuttgart, S. 131-162

BKA. 2001. Bundeskriminalamt: Polizeiliche Kriminalstatistik 2001, http://www.bka.de/pks/pks2001/index2.html, letzter Zugriff 25.10.2009

BKA .2008. Bundeskriminalamt: Polizeiliche Kriminalstatistik 2008, http://www.bka.de/pks/pks2008/download/ pks2008_imk_kurzbericht.pdf, letzter Zugriff 25.10.2009

Boatcă, M. 2003. Die diskursive Macht von Zuschreibungen. Zur Irrfahrt unumstrittener Ergebnisse der Gewaltdebatte. In: Fuchs, M./Luedtke, J. (Hrsg.): Devianz und andere gesellschaftliche Probleme. Opladen, S. 111-130

Boatcă, M. 2009. Lange Wellen des Okzidentalismus. Ver-Fremden von Gender, Rasse und Ethnizität im modernen Weltsystem. In: Dietze, G./Brunner, C.Menzel, E. (Hrsg.): Kritik des Okzidentalismus. Transdisziplinäre Beiträge zu (Neo)Orientalismus und Geschlecht. Bielefeld, S. 233-250

Boatcă, M. Neudecker, C. 2006. Einleitung. Eine interdisziplinäre Sicht auf Dimensionen der Fremdheit. In: Boatcă, M./Neudecker, C./Rinke, S. (Hrsg.): Des Fremden Freund, des Fremden Feind. Fremdverstehen in interdisziplinärer Perspektive. Münster, S. 13-36

Bonß, W. 2002. Riskantes Wissen? Zur Rolle der Wissenschaft in der Risikogesellschaft, in: Heinrich-Böll-Stiftung (Hrsg.): Gut zu Wissen. Links zur Weltgesellschaft, S. 114-130
Butterwegge, C. 2002. Zuwanderungsdiskurse. Migrant(inn) en, multikulturelle Gesellschaft und Rechtsextremismus in den Massenmedien. Vortrag an der Rosa-Luxemburg-Stiftung, http://www.rosalux.de/cms/index.php?id=4730, letzter Zugriff 22.10.2009

Castro-Gómez, S. 2000. Ciencias sociales, violencia epistémica y el problema de la invención del otro. En: Lander, Edgardo (Ed.): La colonialidad del saber: eurocentrismo y ciencias sociale. Perspectivas latinoamericanas, Buenos Aires: CLACSO, S. 145-161

Costa, S. 2007. Vom Nordatlantik zum ,Black Atlantic. Postkoloniale Konfi gurationen und Paradoxien transnationaler Politik. Bielefeld

Descartes, R. 1997. Discours de la méthode pour bien conduire sa raison, et chercher la verité dans les sciences, franz./dt., übers. und hg. von L Gäbe, Hamburg

Dietze, G., Brunner, C., Wenzel, E. (Hrsg.). 2009. Kritik des Okzidentalismus. Transdisziplinäre Beiträge zu (Neo) Orientalismus und Geschlecht. Bielefeld

Geißler, R. 2001. Sind Ausländer krimineller als Deutsche? In: Gegenwartskunde 1/2001, S. 28-41

Geißler, R., Meyer, T. 2008. Die Sozialstruktur Deutschlands: zur gesellschaftlichen Entwicklung mit einer Bilanz zur Wiedervereinigung. Wiesbaden

Goldberg, D. T., Grosfoguel, R. , Mielants, E. 2006. Field of Dream. Cultures of Scholarship and Public Policy on Race in the United State. International Journal of Comparative Sociology. Vol. 47 (3-4), S. 259-280

Grosfoguel, R. 1997. Migration and Geopolitics in the Greater Antilles: From the Cold War to the Post-Cold War, Review 20(1), S. 115-145

Grosfoguel, R. 2003. Colonial Subjects: Puerto Ricans in a Global Perspective, Berkeley: University of California Press

Grosfoguel, R., Georas, C., 2000. Coloniality of Power and Racial Dynamic. Notes Towards a Reinterpretation of Latino Caribbeans in New York City, Identities 7 (1), S. 85-126

Grosfoguel, R., Maldonado-Torres, N., Saldívar, J. D. 2005. Latin@s and the Euro-American Menace. The Decolonization of the U.S. Empire in the Twenty-First Century. In: id. (Eds.): Latin@s in the World-System. Decolonization Struggles in the 21st Century U.S. Empire, S. 3-27

Gutiérrez-Rodríguez, E. 2003. Gouvernementalität und die Ethnisierung des Sozialen - Migration, Arbeit und Biopolitik. In: Pieper, M./Gutiérrez-Rodriguez, E. (Hrsg.): Gouvernementalität. Eine sozialwissenschaftliche Debatte in Anschluß an Foucault. Frankfurt a. M., S. 150-167

Gutiérrez Rodriguez, E. 2005. Das postkoloniale Europa dekonstruieren. Zur Prekarisierung, Migration und Arbeit in der EU, Widerspruch, 48/05. 71-84. 
Ha, K. N., al-Samarai, N. L,Mysorekar, S. (Hrsg.) 2007. re/ visionen. Postkoloniale Perspektiven von People of Color auf Rassismus, Kulturpolitik und Widerstand in Deutschland. Münster

Ha, K. N. 2009. Deutsche Integrationspolitik als koloniale Praxis. In: Dietze, G./ Brunner; C.Menzel, E. (Hrsg.): Kritik des Okzidentalismus. Transdisziplinäre Beiträge zu (Neo)Orientalismus und Geschlecht. Bielefeld, S. 137-150

Habermas, J., 1990. Die Moderne - ein unvollendetes Projekt. In: Ders.: Die Moderne - ein unvollendetes Projekt. Philosophisch-politische Aufsätze 1977-1990. Leipzig, S. 32-54

Hahn, A., 1993. Identität und Nation in Europa. In: Berliner Journal für Soziologie, H. 3, S. 193-203

Hahn, A. 1994. Die soziale Konstruktion des Fremden. In: Sprondel, W. M. (Hrsg.): Die Objektivität der Ordnungen und ihre kommunikative Konstruktion. Frankfurt a. M., S. 140-163

Hahn, A. 2000. Staatsbürgerschaft, Identität und Nation in Europa, in: Holz, Klaus (Hrsg.): Staatsbürgerschaft. Soziale Differenzierung und politische Inklusion, Wiesbaden, S. 53-72

Hanagan, M. 2002. Gewalt und die Entstehung von Staaten, in: Heitmeyer, Wilhelm/Hagan, John (Hrsg.): Internationales Handbuch der Gewaltforschung, Wiesbaden, S. 153-176

Hegel, G. W. F., 1955. Die Vernunft in der Geschichte, hg. von Johannes Hoffmeister, 5. Aufl age, Hamburg: Meiner.

Ignatiev, N. 1995. How the Irish Became White, New York: Routledge

Jäger, M., Cleve, G., Ruth, I., Jäger, S. 1998. Von deutschen Einzeltätern und ausländischen Banden, Duisburg: DISS

Jonas, S. 2006. Reflections on the Great Immigration Battle of 2006 and the Future of the Americas, Social Justice, Vol, 33 (1), S. 6-20

Lamnek, S. 2000. Jugendgewalt in unserer Gesellschaft, in: Gegenwartskunde, 2/2000, S. 237-264

Mies, M. 1996. Patriarchy and Accumulation on a World Scale: Women in the International Division of Labor. London: Zed Books
Mignolo, W. 2000. Local Histories/Global Designs Coloniality, Subaltern Knowledge, and Border Thinking, Princeton

Mucchetti, A. E. 2005. Driving While Brown: A Proposal for Ending Racial Profiling in Emerging Latino Communities, Harvard Latino Law Review, 8, S. 1-32, http://www.law. harvard.edu/students/orgs/IIr/vol8/mucchetti.php, letzter Aufruf 1.11.2009

Nassehi, A. 1990. Zum Funktionswandel von Ethnizität im Prozess gesellschaftlicher Modernisierung, Soziale Welt H.3, S. 261-282

Pedraza-Bailey, S. 1985. Political and Economic Migrants in America: Cubans and Mexicans, Austin: University of Texas Press

Peters, H. 1995. Da werden wir empfindlich. Zur Soziologie der Gewalt. In: Lamnek, S. (Hrsg.): Jugend und Gewalt. Devianz und Kriminalität in Ost und West, Opladen, S. 277-290

Pfeiffer, C. Wetzels, P. 2001. Zur Struktur und Entwicklung der Jugendgewalt in Deutschland: Ein Thesenpapier auf Basis aktueller Forschungsbefunde. In: Oerter, R./Höfl ing, S. (Hrsg.): Mitwirkung und Teilhabe von Kindern und Jugendlichen. München, S. 108-141

Robinson, E. 2007. Driving While Black or Brown, Washington Post, 2.05.2007, http://www.november.org/stayinfo/breaking07/Profi ling.html, letzter Aufruf 1.11.2009

Taylor, P. 2000. Havens and Cage. Reinventing States and Households in the Modern World-System. In: Journal of World-Systems Research, Vol. VI, 2, S. 544-562

Wallerstein, I. 1974. The Modern World-System, New York: The New Press

Wallerstein, I. 1998. Ideologische Spannungsverhältnisse im Kapitalismus: Universalismus v. Sexismus und Rassismus. In: Balibar, E.Mallerstein, I. (Hrsg.): Rasse, Klasse, Nation. Ambivalente Identitäten. Hamburg, S. 39-49

Wallerstein, I. 2003. Citizens All? Citizens Some! The Making of the Citizen. Comparative Studies in Society and History, 45, Vol.4, S. 650-679

Werlhof, C., Mies, M., Bennholdt-Thomsen, V. 1983. Frauen, die letzte Kolonie. In: Technologie und Politik 20, November 1983

\section{Manuela Boatcă}

Professora de sociologia na Freie Universität Berlim, Alemanha. Suas publicaçōes mais recentes: Decolonizing European Sociology. Transdisciplinary Approaches (com Encarnación Gutiérrez-Rodríguez e Sérgio Costa), Farnham: Ashgate, 2010; Catching up with the (New) West. The German "Excellence Initiative", Area Studies, and the Re-Production of Inequality, in: Human Architecture. Journal of the Sociology of Self-Knowledge, 10 (1), 2012; From the Standpoint of Germanism": A Postcolonial Critique of Weber's Theory of Race and Ethnicity, in: Political Power and Social Theory 24, 2013. 